\title{
An unusual presentation of Best's disease
}

\author{
ROBERT C. FLETCHER, ${ }^{1}$ LEE M. JAMPOL, ${ }^{2}$ AND WILLIAM RIMM ${ }^{3}$ \\ From the University of Illinois Eye and Ear Infirmary, Chicago, ${ }^{1,2}$ and the Walter Reed Army Hospital, \\ Washington $^{3}$
}

SUMMARY We diagnosed an unusual case of Best's disease in a patient with multiple geographic macular and extramacular lesions. Initial confusion in the diagnosis arose because of a past history of intravenous drug abuse by the patient. The electro-oculogram was helpful in establishing the correct diagnosis.

Best's hereditary macular degeneration (vitelliform macular dystrophy) was first described in 1905 (Best, 1905). Although most ophthalmologists have a mental image of a 'sunny-side-up egg' becoming a 'scrambled egg', Best's disease may be difficult to recognise clinically. At times extramacular, atypical macular, or multiple lesions may be present (Miller, 1977). We here describe a patient with multiple atypical macular and extramacular lesions in whom a definitive diagnosis was not made until electrophysiological testing was performed.

\section{Case report}

A 19-year-old white man first noted blurred vision in February 1975. He was first seen by an ophthalmologist in August 1975. Visual acuity at that time was 20/20 in the right eye and 20/25-3 in the left eye. Multiple globular subretinal exudates, primarily located superiorly, were described in the posterior poles of both eyes. No diagnosis was made.

The patient's past medical history revealed intravenous drug abuse (cocaine, heroin, and barbiturates) from October 1974 until April 1975 and chronic active hepatitis confirmed by liver biopsy. He was, however, asymptomatic except for his eyes. There was no known history of familial ocular disease.

The patient was next seen in February 1976. His visual acuity was $20 / 20$ in both eyes. The ophthalmoscopic appearance at this time was described as a circinate pattern of deep retinal exudates in the

The opinions or assertions contained herein are the private views of the authors and are not to be construed as official or as reflecting the views of the United States Army or the Department of Defence

Address for reprints: Dr Lee M. Jampol, University of Illinois Eye and Ear Infirmary, 1855 West Taylor Street, Chicago, Illinois 60612, USA posterior poles of both eyes. It was considered possible that the eye findings were somehow related to his past history of drug abuse. The patient's ocular examination, however, remained unchanged during the next month, and he was transferred to the Walter Reed Army Medical Center for further evaluation.

We first saw the patient on 18 March 1976. Visual acuity was 20/20 bilaterally. Results of slitlamp biomicroscopy and applanation tonometry were normal. Dilated examination of the fundus showed bilateral, multiple, discrete, and confluent geographic yellowish lesions in either the deep retina or in the pigment epithelium (Figs. 1-3). Goldman perimetry showed bilateral relative paracentral scotomas. Fluorescein angiography disclosed blocking of the choroidal fluorescence by the lesions (Fig. 4). Electroretinography, dark adaptometry, and colour vision testing were all normal. Electro-oculography showed a light-peak to dark-trough ratio of 1.35 in the right eye and 1.23 in the left eye (normal is greater than 1.65). A definite diagnosis of Best's disease was made.

\section{Discussion}

Best's hereditary macular degeneration is a welldescribed entity but is sufficiently uncommon in clinical practice to cause confusion in diagnosis. The ophthalmoscopic appearance may include a normal fovea, vitelliform lesions, macular cysts, pseudohypopyons, or chorioretinal atrophy (Falls, 1969; Maloney et al., 1977). The lesions may be bilateral or unilateral, single or multiple, macular or eccentric (Falls, 1969; Miller, 1977).

The inheritance of Best's disease is thought to be autosomal dominant with variable penetrance and expressivity (Deutman, 1971). The age range of the patients at the time of presentation varies from 


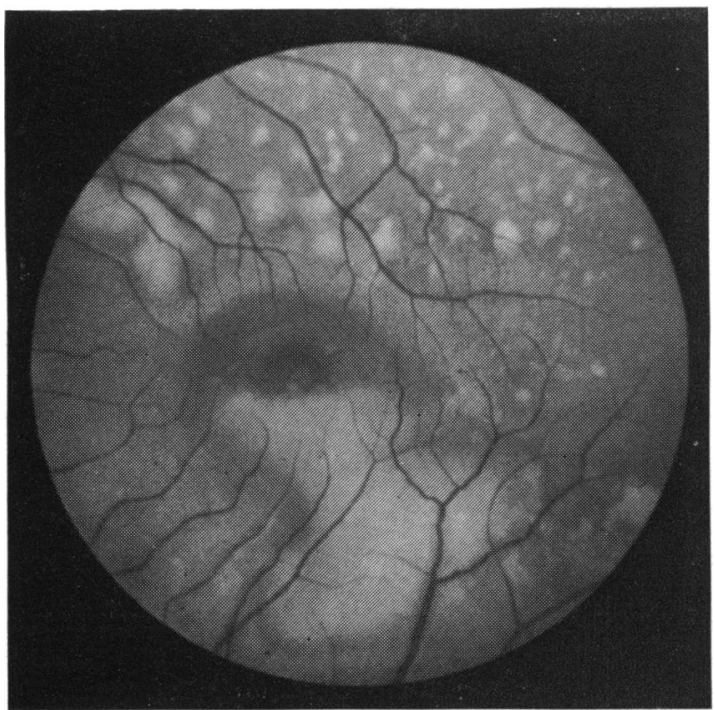

Fig. 1 Posterior pole of left eye showing pseudohypopyon in a large geographic lesion and multiple smaller lesions

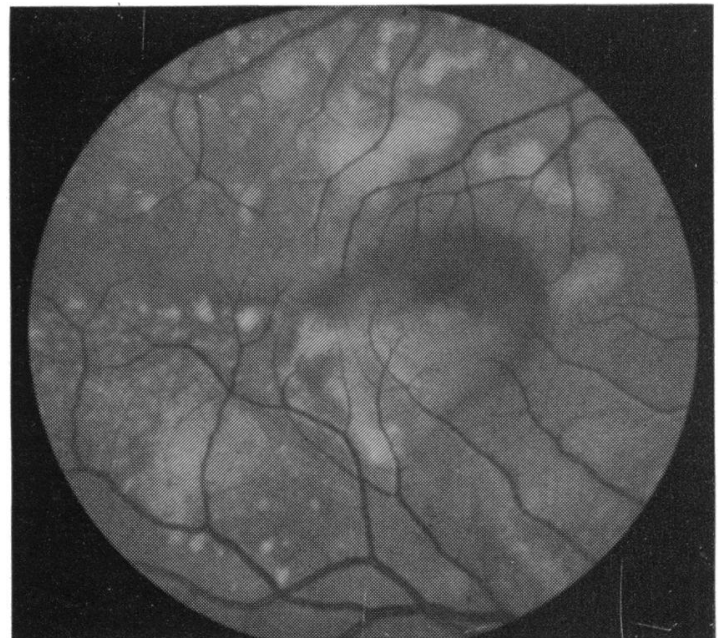

Fig. 2 Similar appearance of the right posterior pole

1 week to 74 years (Deutman, 1971). Because the penetrance and expressivity may be variable, a patient who has an atypical lesion may be unaware of other family members similarly affected, and, therefore, will not provide the examiner with this potentially valuable clue. The electroretinogram and dark adaptation findings are often normal (Fishman, 1975). Colour vision may be mildly or markedly abnormal, the degree depending on the extent of the macular damage (Krill and Archer, 1977). Fluorescein angiography discloses blockage of choroidal fluorescence by the lesion, which is not characteristic enough to lead to a definitive diagnosis. Fluorescein studies have shown in some cases a choroidal neovascular membrane within the ruptured vitelliform lesion (Miller et al., 1976). The electrooculogram, with few exceptions, is subnormal and it can be helpful in diagnosing apparently normal carriers, subtle early cases, or, as in our patient, atypical presentations.

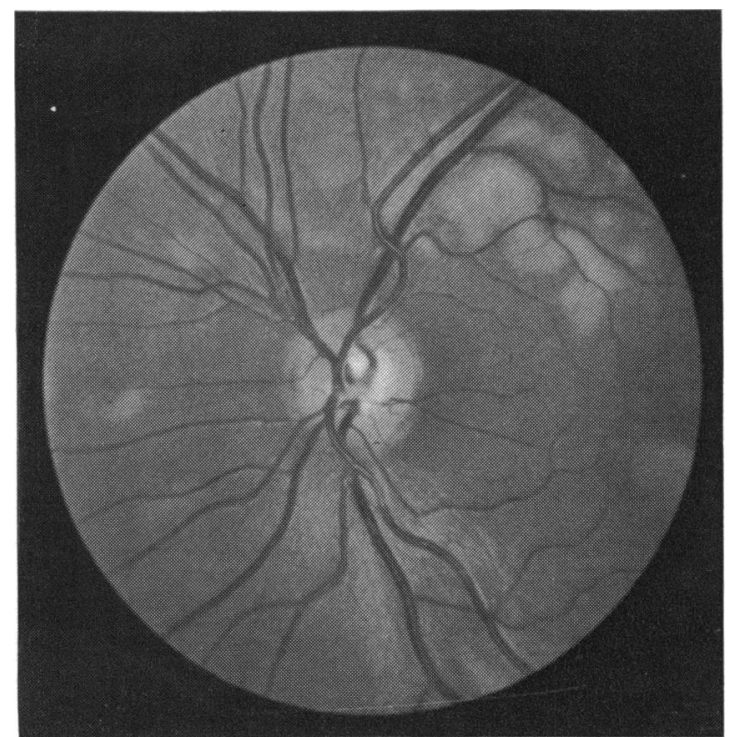

Fig. 3 Peripapillary area of the left eye showing nasal location of some of the lesions as well as macular involvement

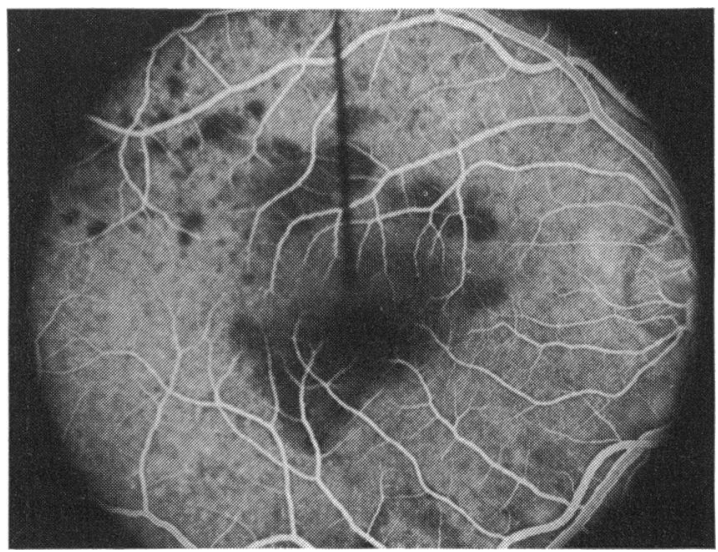

Fig. 4 Fluorescein angiogram (late venous phase) of the right eye showing blocked choroidal fluorescence corresponding to some of the lesions. Other fainter lesions do not block the choroidal fluorescence 
We thank Ken Kramer, MD, who performed the electrophysiological testing, and Ellen Foer, who performed the photography.

\section{References}

Best, F. (1905). Über eine hereditare Maculaaffektion. Beitrage zur Vererbungslehre. Zeitschrift für Augenheilkunde, 13, 199-212.

Deutman, A. F. (1971). The Hereditary Dystrophies of the Posterior Pole of the Eye. 1st ed., pp. 198-299. Charles C Thomas: Springfield, Illinois.

Falls, H. F. (1969). The polymorphous manifestations of Best's disease (vitelliform eruptive disease of the retina). Transactions of the American Ophthalmological Society, 67, 265-279.
Fishman, G. A. (1975). The Electroretinogram and Electrooculogram in Retinal and Choroidal Disease. 1st ed., pp. 27-28, 39, American Academy of Ophthalmology and Otolaryngology: Rochester, Minnesota.

Krill, A. E., and Archer, D. B. (1977). Krill's Hereditary Retinal and Choroidal Diseases, Vol. 2, 1st ed., pp. 665-704. Harper \& Row: Hagerstown, Maryland.

Maloney, W. F., Robertson, D. M., and Duboff, S. M. (1977). Hereditary vitelliform macular degeneration. Archives of Ophthalmology, 95, 979-983.

Miller, S. A., Bresnick, G. H., and Chandra, S. R. (1976). Choroidal neovascular membrane in Best's vitelliform macular dystrophy. American Journal of Ophthalmology, 82, 252-255.

Miller, S. A. (1977). Multifocal Best's vitelliform dystrophy. Archives of Ophthalmology, 95, 984-990. 